\title{
Olhares fronteiriços a partir de estudos da fronteira na Amazônia
}

MARTINS, José de Souza. Fronteira: a degradação do Outro nos confins do humano. $2^{a}$ ed. São Paulo: Ed. Contexto, 2014.

\section{Eliana Campos POJO' \\ FAECS/UFPA elianapojo@ufpa.br}

José de Souza Martins, docente pesquisador e intelectual de processos sociais, traz nesta obra a instigante problematização, a dos encontros e desencontros na/da fronteira. $\mathrm{O}$ livro é formulado com base em pesquisas desenvolvidas ao longo de trinta anos, metade dos quais em diferentes ocasiões e em diferentes pontos da região amazônica (p. 11).

Na obra, Martins assume o desafio de refletir sobre a apropriação do trabalho humano pelo capitalismo contemporâneo, em especial nos territórios de fronteira no interior do Brasil, todas marcadas pela degradação do humano.

Baseado na concepção marxiana do desenvolvimento desigual do capitalismo, o docente pesquisador destaca que a contradição posta pela existência do trabalho escravo na atual fase do capitalismo precisa ser compreendida como "um componente do próprio processo do capital” (Martins, 2014, p.78), diferenciando da escravidão que perdurou até o século XIX, ainda que apresentando similaridades com a coerção e a privação da liberdade dos trabalhadores nos dias atuais. Mostra-nos que o capitalismo engendra contornos específicos, alterando formas de organização social, da gestão do Estado e da organização do trabalho e, principalmente, marca outra forma de posicionamento humano em relação ao outro.

O livro apresenta quatro capítulos, direcionados pelas dimensões Frentes de Expansão e Pioneira no Brasil, a partir de uma técnica denominada pelo autor como pedagogia investigativa. Sua análise parte das dimensões, cuja aproximação e confronto constituem o fio condutor dos textos, demonstrando que este procedimento analítico é necessário para a compreensão da fronteira.

\footnotetext{
${ }^{1}$ Professora Faculdade de Educação, da UFPA-Campus de Abaetetuba. Doutoranda de Ciências Sociais do IFCH/UNICAMP.
} 
Tais dimensões representam momentos históricos distintos em diferentes modalidades da expansão territorial do capital [...] expressões de um mesmo processo. (p.170, nota 20)

Se entendermos que a fronteira tem dois lados e não um lado só, o suposto lado da civilização; se entendermos que ela tem o lado de cá e o lado de lá, fica mais fácil e mais abrangente estudar a fronteira como concepção de fronteira do humano. Nesse sentido, diversamente do que ocorre com a frente pioneira, (na frente de expansão) sua dimensão econômica é secundária. (p.141)

Nessa direção instiga-nos a pensar o conceito para além dos territórios distantes que analisou:

A fronteira de modo algum se reduz e se resume à fronteira geográfica. Ela é fronteira de muitas e diferentes coisas: fronteira da civilização (demarcada pela barbárie que nela se oculta), fronteira espacial, fronteira de culturas e visões de mundo, fronteira de etnias, fronteira da história e da historicidade do homem. E, sobretudo, fronteira do humano (MARTINS, 2014, p.11).

No primeiro capítulo A captura do outro: o rapto de mulheres e crianças nas fronteiras étnicas do Brasil, parte de um conjunto de documentos oriundos da pesquisa, acentuando indicadores dos desencontros das frentes de expansão que é o do rapto de pessoas, principalmente de mulheres e crianças pelos grupos tribais entre si e, também, pelos indígenas em relação aos regionais e pelos regionais em relação ao índio.

A reprodução do capital na frente pioneira e o renascimento da escravidão é o segundo capítulo. Aqui Martins detém-se sobre a frente pioneira - que é, um dos momentos de um mesmo processo, ou seja, o da reprodução do capital. (p.74) Faz uma crítica a determinadas formulações teóricas que obscurecem compreender

as contradições engendradas pelo capital, em seu processo de reprodução ampliada, incluem formas sociais e mediações formais, como é o caso da escravidão por dívida, diversas de suas outras manifestações formais, como a do trabalho livre. (p.73-74)

O terceiro capítulo intitulado Regimar e seus amigos: a criança na luta pela terra e pela vida. Discorre sobre o que se convencionou na sociologia, o trabalho com informantes privilegiados e, põe em cena, outros sujeitos e suas histórias: “as mulheres, as crianças, os 
velhos, os agregados da casa, os dependentes, os que vivem de favor. Ou os mudos da História, os que não deixam textos escritos”. (p.104) Assim, privilegia os depoimentos de crianças e adolescentes em um núcleo de colonização particular (Colônia de Canarana no Mato Grosso) e em dois povoados (São Pedro da Água Branca e Floresta, no Maranhão). Assim justifica: "Neste texto falo da fala das crianças, que por meio delas me falam (e nos falam) do que é ser criança (e adulto) nas remotas regiões das frentes de ocupação do território, em distantes pontos da Amazônia" (p.106).

O tempo da fronteira: retorno à controvérsia sobre o tempo histórico da frente de expansão e da frente pioneira forma o quarto capítulo e é a parte mais densa da obra. Aqui, o autor argumenta que, na contemporaneidade brasileira, o que há de sociologicamente mais relevante para definir a fronteira no Brasil é, justamente, a situação de conflito social (p.133). De acordo com o autor:

...a situação de fronteira (é) um ponto de referência privilegiado para a pesquisa sociológica porque encerra maior riqueza de possibilidades históricas do que outras situações sociais. Em grande parte porque mais do que o confronto entre grupos sociais com interesses conflitivos, agrega a esse conflito também o conflito entre historicidades desencontradas (p.154).

Este esforço levou-o a concluir que a fronteira não se reduz à questão geográfica:

Ela é fronteira de muitas e diferentes coisas: fronteira da civilização (demarcada pela barbárie que nela se oculta), fronteira espacial, fronteira de culturas e visões de mundo, sobretudo, fronteira do humano. Nesse sentido, a fronteira tem um caráter litúrgico e sacrificial, porque nela o outro é degradado para, desse modo, viabilizar a existência de quem o domina, subjuga e explora. É nessa dimensão, propriamente sociológica e antropológica, que investigo o tema da fronteira e os desafios que propõe em relação à sociedade em que vivemos e em relação à nossa própria condição humana (p.11).

Martins (2014) traz em sua obra, além do fecundo estudo sobre situações e questões fronteiriças na Amazônia brasileira, também destaca aspectos metodológicas que são úteis aos pesquisadores e docentes, em especial, das ciências humanas envolvidos com fazeres e aprendizados de pesquisa: as implicações teóricas, os compromissos, as dificuldades, o 
perigo das posições ambíguas, o trabalho solitário, as situações dos contextos em que o pesquisador se envolve, em suma, questões postas a posição política do fazer pesquisa. Ademais, a obra é instigante para o aprofundamento do referencial sociológico do autor em sua rica composição temática que perpassa a questão agrária, o camponês e o campesinato brasileiro, capitalismo entre outros aspectos, sempre ancorado por um diálogo com a dinâmica social do país.

O docente pesquisador José de Souza Martins em suas obras acentua questões da realidade social brasileira e de forma relacional, o compromisso social com a pesquisa. Justifica-se a indicação da leitura minuciosa para melhor compreendermos os dilemas que envolvem a construção da identidade nacional brasileira, tão bem expressada pelo autor:

Nossa identidade nacional se constrói sobre o canibalismo simbólico que devora no outro o que queremos ser, na constituição problemática de um nós edificado sobre a alteridade intolerante de uma visão missionária do mundo e do homem. É na fronteira que nasce o brasileiro, mas é aí também que ele se devora nos impasses de uma história sem rumo. Decifrar a fronteira fundante do que somos é mergulhar nos desvendamentos por meio dos quais podemos nos reconhecer no conhecimento do que a sociedade brasileira é. (p.21)

\section{O rio como fronteira: aspectos de sociabilidade e cultura(s) ${ }^{2}$}

Emprestamos a ideia do autor em relação as diversas compreensões e visões dada a fronteira para sinalizar, ainda que prematuramente, a interface com o rio fronteiriço.

Trata-se do rio Baixo Itacuruça, lugar de encanto na Amazônia Paraense, localizado no município de Abaetetuba, nordeste do estado. Assumimos a caracterização de rio-mar ${ }^{3}$ devido sua extensão, beleza e contraste social ímpar. Na comunidade que fica às margens

2 A interface é fruto das incursões ao campo na comunidade que vem sendo desenvolvida desde 2012. Inicialmente, por meio de dois projetos: o Projeto Integrando Conhecimentos e Saberes: uma experiência educativa na primeira escola quilombola de Abaetetuba-PA e o Projeto de pesquisa Travessias, identidades e saberes das águas - Cartografia de saberes de populações ribeirinhas no município de Abaetetuba-PA. Tais projetos enfatizaram os saberes populares na mediação com processos educacionais do lugar, potencialmente.

3 Concebemos a ideia que caracteriza o rio para além da geografia, a qual admite uma dualidade entre rio e mar. Cultiva-se a concepção de mar que é rio e de rio que é mar por se vivenciar na Amazônia a existência de um rio-mar que não é metafórico, é literal, ou seja, não existe do mar ou do rio, porque o rio é mar. Ou, Opará, utilizando a construção indígena para o significado de rio-mar. 
desse rio, há outros rios como o Arapapu e o Arapauzinho, há o furo do gaita e ainda, vários igarapés, constituindo uma paisagem fronteiriça adicionado à floresta e suas gentes.

Nesse pedaço da Amazônia há uma natureza qualitativamente distinta - relações de vizinhança e parentesco, mutirões em atividades de trabalho nas roças, práticas artesanais, em suma, dinamizam significações socioculturais. Nesse saber-fazer, a imbricação com o rio-mar é peculiar, assim desde cedo, as crianças pilotam e passeiam nas embarcações (rabetas e cascos), brincam e banham-se cotidianamente. É costumeiro se ouvir das pessoas do lugar "a gente foi criado n’água”, assim como, expressam modos de lidar com ele: pela disposição em navegar dia a dia nas águas; por possuirem conhecimento sobre a 'essência viva' das marés vazantes, cheias, de lance, de quebra; por saberem, com precisão o tempo das águas e a relação com as fases da lua, confirmando um dado saber das águas. Junto a esse afeto, se entrelaça a crença lendária na Matinta Pereira, no Boto, na Cobra Grande, enquanto simbologias do habitar naquele território margeado por águas.

A compreensão ampla e própria da fronteira enfatizada por Martins associa-se às dinâmicas sociais em territórios e situações de vida diversas, o do humano no processo capital sendo a fronteira vista para além do aspecto geográfico. Sob esse prisma, vemos múltiplas sociabilidades em relações comunicativas postas pelo território-rio enquanto lugar social e signo.

Assim, a análoga ideia do rio fronteiriço assenta-se pela sua forma de expressão cultural. Ele junta, dinamiza, espacializa, atravessa e é atravessado por suas gentes. Mas, é também ponto de divergência. De conflitos. Atritos ocorrem por e nos espaços e tempos do rio.

São ribeirinhos e quilombolas que estão, de um lado e de outro, do rio, e, embora os lados constituam territórios próprios desses povos, suas práticas de uso e travessia é, em certa medida, imbricada. Há relações e sociabilidades entre eles pelo que lhes é comum, o rio Baixo Itacuruça.

Se misturam, ribeirinhos e quilombolas, por meio de ações e trocas que acontecem, como por exemplo, no uso dos espaços no rio para a pesca do camarão com matapi, no serviço prestado pela escola que fica também naquele rio, no uso dos trapiches onde 
ancoram suas embarcações à beira-rio, na circulação das embarçações no ir e vir pelo rio, na ajuda mútua quando alguma canoa fica encalhada ocasionado pela maré seca ou, ainda, quando alguém pede carona, entre outras formas. Nesse atravessamento por entre o rio Itacuruça e os demais rios e igarapés vivenciam a fronteira do humano, em que são absorvidos aprendizados que comunicam um dado viver no lugar.

O rio fronteiriço traduz-se num locus de interatividade e, também, de discussões humanas e territoriais, mas eminentemente, na/da travessia do/pelo rio se processa ricas experiências étnicas, de classe, de visões de mundo, de vizinhança, de trabalho e de afeto no fluxo cotidiano da comunidade. Ele, tanto funciona como espaço de deslocamento e de percurso, quanto, de interação com a floresta, expressada por costumes, jeitos, tempos, cultura(s) que marcam um viver de homens e mulheres desse lugar na Amazônia.

Tomado sob a dimensão social, o rio é fluxo temporal de cultura(s) que modificamse constantemente e alteram o pensar dos sujeitos. Configura-se a confluência que afasta e une pessoas e fazeres, lugar da alteridade. (Martins, 2014, p.133)

Atravessados pela natureza em que o rio fronteiriço é parte, homens e mulheres de lá vivem seus desencontros e parcerias desnudando imbricações econômicas, culturais, sociais, simbólicas, geográficas que formam 'maresias' identitárias do humano no lugar. 